\title{
InAsN/InGaAs/InP Quantum Well Structures for Mid-Infrared Diode Lasers
}

\author{
H. H. Lin, D. K. Shih, Y. H. Lin and K. H. Chiang \\ Department of Electrical Engineering and Graduate Institute of Electronics Engineering \\ National Taiwan University, Taipei, Taiwan, R.O.C.
}

\begin{abstract}
Many spectroscopic and medical applications require lasers with emission wavelength of 2-3 $\mu \mathrm{m}$. Besides the traditional Sb-based alloys lattice-matched to GaSb substrate, strained InAsN/nnGaAs quantum-well $(\mathrm{QW})$ structure on $\mathrm{InP}$ substrate is a potential alternative for laser devices in this spectral range [1]. InAsN owns two important features, i. e., the band gap reduction due to the huge bowing parameters induced by the large differences in atomic sizes and electronegativities of $\mathrm{N}$ and As atoms [2] and the lattice-mismatch-reduction when it is grown on InP substrates. Both features can extend the wavelength range of InAsN/InGaAs QW and make it a promising material for mid-infrared applications. In addition, the superior quality of InP substrates over GaSb substrates and the mature growth and processing technologies on InP-related alloys also provide advantages for laser diodes based on InAsN/InGaAs QW structures.
\end{abstract}

In this study; InAsN/In $\mathrm{In}_{0.53} \mathrm{Ga}_{0.47} \mathrm{As}$ multiple quantum wells (MQWs) and laser structures were grown on (100) InP substrates by using a VG V-80H gas-source molecular beam epitaxy (GSMBE). Besides the elemental In and $\mathrm{Ga}$ and thermally cracked $\mathrm{AsH}_{3}$ and $\mathrm{PH}_{3}$ sources, an EPI UNI-bulb RF plasma cell was used to generate active nitrogen species. The optimized growth temperature and growth rate for InAsN were $400^{\circ} \mathrm{C}$ and $1.5 \mu \mathrm{m} / \mathrm{hr}$, respectively. Photoluminescence (PL) measurement on InAsN/InGaAs MQWs with various nitrogen compositions shows that the nitrogen increment in InAsN results in red-shift on the PL emission wavelength. X-ray diffraction measurement on these MQWs also indicates that nitrogen incorporation can reduce the net compressive strain of the MQW [3]. The PL integrated intensity of the InAsN QW with 3\% nitrogen composition is comparable to that of the high-quality strained InAs/InGaAs QW. [4]. However, further nitrogen incorporation degrades the PL intensity significantly. Therefore, 4-period $\ln \mathrm{AsN} / \mathrm{In}_{0.53} \mathrm{Ga}_{0.47} \mathrm{As}$ MQW with $3 \%$ nitrogen composition was chosen for the active medium of the laser. The detailed laser structure is shown in Fig. 1. After the GSMBE growth, the laser sample was annealed at $575^{\circ} \mathrm{C}$ for $20 \mathrm{~min}$ under $\mathrm{N}$ ambient in order to improve the crystal quality [5]. - The PL spectrums of the laser structure before and after annealing are shown in Fig. 2. The structure was then processed into $50-\mu \mathrm{m}$-wide broad-area lasers. Laser oscillation under pulsed injection current was obtained from $10 \mathrm{~K}$ to $260 \mathrm{~K}$. Fig. 3 shows the emission spectrum at $260 \mathrm{~K}$. As can be seen, the peak wavelength is at $2.42 \mu \mathrm{m}$. The threshold current density of the laser at $260 \mathrm{~K}$ is 6.2 $\mathrm{kA} / \mathrm{cm}^{2}$, and the characteristic temperature is $110 \mathrm{~K}$ for a temperature range from 50 to $260 \mathrm{~K}$. The laser performances indicate the potential of InAsN as a material for mid-infrared applications. 
This work was supported by the National Science Council and the Education Ministry of the Republic of China.

\section{References}

[1] D. K. Shih, H. H. Lin, and Y. H. Lin, Electronics Letters, 37(2), 1342, 2001.

[2] S. H. Wei and A. Zunger, , Phys. Rev. Lett., 76 (4), 664, 1996.

[3] J. S. Wang, H. H. Lin, L. W. Sung, and G R. Chen, J. Vac. Sci. Technol. B, 19(1), 202-206, 2001.

[4] D. K. Shih, H. H. Lin, and Y. H. Lin, IEE Proceedings - Optoelectronics, in press

[5] J. S. Wang and H. H. Lin, J. Vac. Sci. Technol. B, vol. 17, no. 5, pp.1997-2000, 1999.

\begin{tabular}{|c|c|c|c|}
\hline Layer & Material & Thickpess & Doping $\left(\mathrm{cm}^{-3}\right)$ \\
\hline Protection & $\ln P$ & $30 \mathrm{~nm}$ & $\mathrm{p}-3 \times 10^{19}$ \\
\hline \multirow[t]{3}{*}{ Obmic Contact } & $\ln _{0,53} \mathrm{Ga}_{0,47} \mathrm{As}$ & $0.1 \mu \mathrm{m}$ & $p-3 \times 10^{19}$ \\
\hline & $\ln \mathrm{P}$ & $0.3 \mu \mathrm{m}$ & $p-8 \times 10^{11}$ \\
\hline & InP & $0.5 \mu \mathrm{m}$ & $p-1 \times 10^{11}$ \\
\hline \multirow[t]{3}{*}{ Cladding } & InP & $0.5 \mu \mathrm{m}$ & $0-5 \times 10^{17}$ \\
\hline & $\mathrm{InP}$ & $0.3 \mu \mathrm{m}$ & $p-2 \times 10^{17}$ \\
\hline & InP & $0.1 \mathrm{\mu m}$ & \\
\hline Barrier & $\mathrm{In}_{0,33} \mathrm{G}_{\mathrm{a}_{0,4}} \mathrm{As}$ & $86 \mathrm{~nm}$ & \\
\hline Barrier & $\mathrm{I}_{0,53} \mathrm{Ga}_{0,4} \mathrm{As}$ & $40 \mathrm{~nm}$ & \\
\hline Well & InAs $s_{0.97} \mathrm{~N}_{0.03}$ & $3 \mathrm{~nm}$ & \\
\hline Bartier & $\mathrm{In}_{0,53} \mathrm{Ga}_{0,47} \mathrm{As}$ & $126 \mathrm{~nm}$ & undoped \\
\hline Buffer & $\mathrm{n}-\operatorname{In} \mathrm{P}$ & $0.5 \mu \mathrm{m}$ & $n-1 \times 10^{13}$ \\
\hline Substrate & $\mathrm{a}^{+}-\ln \mathrm{P}$ & & \\
\hline
\end{tabular}

Fig. 1 Structure of the InAsN/InGaAs quantum well laser diode.

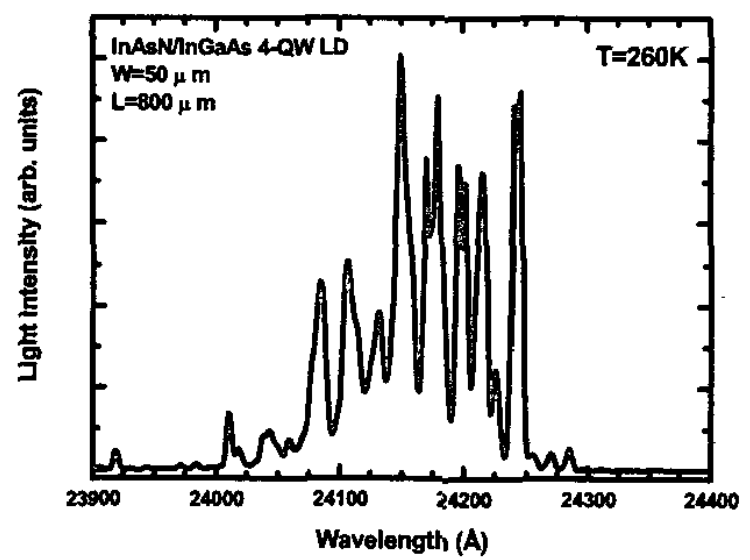

Fig. 3 Emission spectrum of InAsN/InGaAs diode laser operated at $260 \mathrm{~K}$.

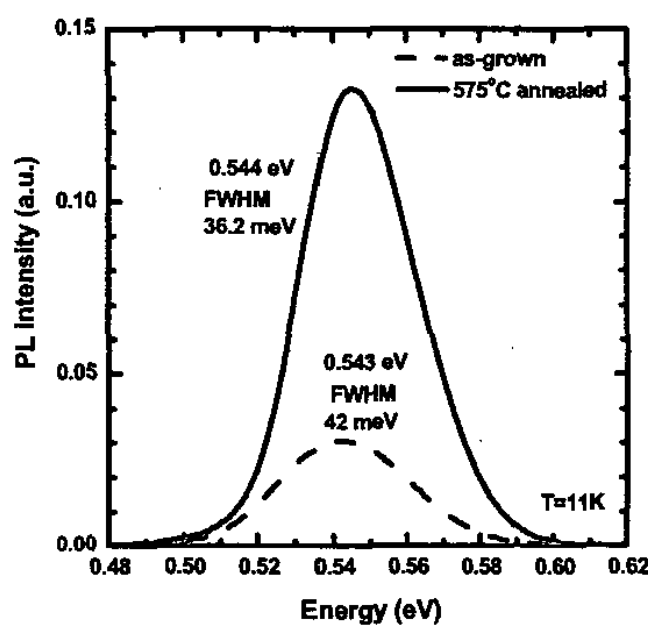

Fig. $211 \mathrm{~K}$ PL spectrums of the as-grown and annealed 4-period InAsN/ InGaAs quantum well laser. 